\title{
ESTAMPA POPULAR DE VIZCAYA. LA CREACIÓN PLÁSTICA COMO INSTRUMENTO DE ACCIÓN POLÍTICA*
}

\author{
Alice Cearreta-InNOCEnTI ${ }^{1}$ \\ Universidad Autónoma de Madrid
}

\begin{abstract}
Estampa Popular de Vizcaya se constituyó en los años 1960 como un grupo integrante de la red de artistas antifranquistas Estampa Popular gracias a Agustín Ibarrola, María Francisca Dapena y Dionisio Blanco, todos ellos comprometidos en la lucha contra la dictadura y por las libertades. En este trabajo se estudia la producción de estos artistas durante el corto período de vida del grupo analizando las estampas desde su materialidad. Este tipo de aproximación permite recuperar la capacidad de agencia de la creación artística y valorar cómo afecta a la obra de arte su puesta en valor al transformarse en pieza de museo, así como los procesos de actualización que provocan los nuevos discursos.

Palabras clave: Estampa Popular; grabado; arte comprometido; franquismo; País Vasco.
\end{abstract}

\section{ESTAMPA POPULAR DE VIZCAYA. ARTISTIC CREATION AS AN INSTRUMENT OF POLITICAL ACTION}

Estampa Popular de Vizcaya was born in the 1960s as part of the network of anti-Franco artists Estampa Popular under the initiative of Agustín Ibarrola, María Francisca Dapena and Dionisio Blanco. All of them were committed to the fight against the dictatorship and in support of political freedom. This paper explores the work of these artists during the brief period the group was active, and analyses the prints in terms of their material aspect. This type of approach permits comprehension of the capacity of artistic creation to effect change. It also allows for the assessment of how the appreciation of a work of art is affected when it is transformed into a museum piece.

Key words: Estampa Popular; engraving; politically committed art; Franco period; Basque Country.

Cómo citar este artículo / Citation: Cearreta-Innocenti, Alice (2017): "Estampa Popular de Vizcaya. La creación plástica como instrumento de acción política". En: Archivo Español de Arte, vol. 90, núm. 358, Madrid, pp. 155-170. doi: $10.3989 /$ aearte. 2017.10

\section{Introducción}

Como es sabido, Estampa Popular fue una red de artistas antifranquistas que emplearon el grabado como arma de lucha y resistencia política contra la dictadura durante la década de 1960

\footnotetext{
* Este artículo ha sido elaborado a partir del Trabajo Fin de Máster "Estampa Popular de Vizcaya: contextos y referentes. La creación plástica como instrumento de acción política" desarrollado en el marco del Máster en Historia del Arte Contemporáneo y Cultura Visual, impartido por la Universidad Autónoma de Madrid, la Universidad Complutense de Madrid y el Museo Reina Sofía (2013/2014). Deseo dar las gracias a mi tutora Dra. Jesusa Vega por su dedicación y seguimiento, al evaluador/a anónimo/a cuyas atentas observaciones han permitido mejorar el manuscrito original y a las siguientes personas por su gran ayuda durante el desarrollo del trabajo: Irrintzi Ibarrola, Agustín Ibarrola, Gaizka Villate, Sol Panera, Olga Seco, Valeria García-Landarte, Maite Martínez, Nuria García, Lucía Cabezón, Carmen Román y Javier Madariaga.

1 alice.cearreta@gmail.com / ORCID iD: http://orcid.org/0000-0002-3644-0599.
} 
en diversas regiones de España. El primer núcleo nació en Madrid en 1959 a iniciativa de un grupo de artistas socialmente comprometidos e interesados en llevar a la práctica una concepción del arte como instrumento de acción cercano al pueblo. A partir de este grupo primigenio y gracias al impulso dado por José Ortega fueron surgiendo otras formaciones en Sevilla, Córdoba, Vizcaya, Valencia, Cataluña y Galicia. Ortega dedicó un gran esfuerzo en movilizar a los artistas para que se sumaran a la lucha antifranquista a través del grabado. Sus esfuerzos dieron fruto y Estampa Popular fue constituyéndose como una $\mathrm{red}^{2}$, una auténtica tela de araña que fue tejiéndose por todo el país.

El objetivo principal que unía a estos artistas plásticos era llevar el arte al pueblo, un arte de calidad a través de un medio y un lenguaje adecuados que lo hicieran socialmente útil y que plasmasen la realidad política y social del momento. El grabado resultaba la técnica más propicia, pues permitía la multiplicación serial de las obras con su consiguiente abaratamiento y una amplia posibilidad de difusión, así como su estampación con técnicas artesanales y materiales fácilmente asequibles. No existía ningún postulado común más allá de los principios éticos y políticos compartidos y, aunque varios artistas eran miembros del PCE, fue la conciencia antifranquista lo que realmente acomunaba a todos, así como la aceptación del realismo como referente estético. Tampoco había ningún tipo de imposición en cuanto a la temática a desarrollar y se emplearon diferentes lenguajes plásticos y técnicas según las circunstancias, inquietudes y peculiaridades de cada agrupación.

De este modo, los artistas vascos defendieron en sus obras señas de identidad propias, es decir, sus obras conectaban, por un lado, con las circunstancias particulares del contexto obrero del País Vasco y, por el otro, con los precedentes de la tradición pictórica vasca. En este sentido, aunque la genealogía de los referentes estéticos y temáticos de los que resultarían herederos tanto Agustín Ibarrola como María Dapena trascienden los límites de este ensayo ${ }^{3}$, merece la pena señalar que ambos emplean ciertas codificaciones morfológicas que se suelen identificar con una estética vasca, como la prevalencia de formas escultóricas y geométricas y un particular sentido del dinamismo dado por el uso de las diagonales ${ }^{4}$. Estas características formales fueron empleadas por los artistas para representar la realidad de una Euskadi sin discriminación "en razón de raza ni de lugar, de procedencia de las personas (sic)" ${ }^{5}$. Lejos de adjetivaciones excluyentes, por tanto, la representación del pueblo vasco, de los topoi del arrantzale (pescador), del baserritarra (campesino) o del obrero, está constituida por quienes viven y trabajan en el País Vasco $^{6}$.

\section{Nacimiento de Estampa Popular de Vizcaya}

A finales de 1959 Agustín Ibarrola conoció en París a José Ortega, quien introdujo al artista vasco en el mundo del grabado y le alentó a fundar Estampa Popular de Vizcaya. A su regreso al País Vasco en 1961 Ibarrola intentó reanimar la Asociación Artística Vizcaína e impulsó Estampa Popular de Vizcaya ${ }^{7}$, en cuya aventura le acompañaron María Dapena y Dionisio Blanco ${ }^{8}$.

\footnotetext{
2 Aunque en la historiografía es frecuente encontrar a Estampa Popular presentada como un movimiento, preferimos considerarlo una "red" en los términos definidos por N. de Haro (De Haro, 2010: 360) al prevalecer el carácter abierto y articulado de este conjunto de artistas.

3 A este respecto nos remitimos, entre otros, a García-Landarte, 2006: 397; Agirre/Garmendia/Martínez, 1991: 1435 en el caso de Ibarrola; y Retana, 1980: 2 y 3, y Macazaga, 2014: 435-437 en el caso de Dapena.

${ }^{4}$ Guasch, 1985: 228. Angulo, 1978: 340.

5 Angulo, 1978: 329.

6 Véase Ibarrola en Guasch, 1985: 297 y 298.

7 De Haro, 2010: 180. Macazaga, 2013: 184.

8 A pesar de que Estampa Popular de Vizcaya haya sido siempre recordada en la historiografía acerca de Estampa Popular, han sido pocos los estudios que se han centrado exclusivamente en el grupo vizcaíno y, tras el fin de la actividad del colectivo, tampoco se ha celebrado ninguna exposición monográfica dedicada a esta agrupación de artistas.
} 
En realidad, como el mismo Ibarrola señala, "los presupuestos ideológicos" sobre los que se fundamentó Estampa Popular de Vizcaya no eran nuevos ni en su actividad ni en la realidad artística del País Vasco, sino que "venían desarrollándose clara y contundentemente desde 1950". La diferencia en esta ocasión es que se hizo "a través de los procesos de la obra múltiple del grabado" . Ya en 1954, de hecho, varios artistas e intelectuales como Agustín Ibarrola, María Dapena e Ismael Fidalgo y los poetas Blas de Otero, Sabina de la Cruz, Vidal de Nicolás, Emiliano Serna o Julián Viejo, realizaron un conjunto de actividades culturales y exposiciones itinerantes por diferentes pueblos vizcaínos. Generalmente se intentaba que éstas coincidieran con las fiestas populares, pues se pretendía, como ocurriría algunos años después con Estampa Popular de Vizcaya, acercar el arte al pueblo y crear un tejido socio-cultural alejado de los circuitos oficiales controlados por la censura franquista ${ }^{10}$. Esta colaboración entre artistas, poetas y críticos continuó durante la etapa de Estampa Popular gracias al fuerte vínculo que unía a artistas y literatos, entre los que también se encontraban Gabriel Aresti, Gabriel Celaya y Antonio Giménez Pericás.

Esta estrecha relación se materializó, por ejemplo, en la implicación de algunos de los citados intelectuales en las actividades de Estampa Popular de Vizcaya, como es el caso de las dos exposiciones que el grupo realizó en 1962, antes de que fueran encarcelados la mayoría de sus componentes. La primera de estas exposiciones, que contó además con la participación de José Ortega y Valentín Ruiz Morquecho ${ }^{11}$, se celebró en los bajos del ayuntamiento de San Sebastián entre el 9 y el 23 de marzo. El programa para esa quincena incluyó recitales de poesía y una conferencia a cargo de Giménez Pericás. El catálogo que se publicó para la ocasión contenía poesías de Gabriel Aresti, Sabina de la Cruz y Vidal de Nicolás, así como un ensayo de Antonio Giménez Pericás sobre el tema del realismo.

Estos mismos intelectuales, junto a Blas de Otero y Carlos Álvarez, participaron también en la segunda exposición, celebrada en Córdoba durante el mes de mayo de ese mismo año y titulada Arte Norte y Sur, cuyo catálogo los presentaba como "poetas de Estampa Popular de Vizcaya". Además de los grabadores vascos, expusieron integrantes del Grupo Sevilla, de Estampa Popular de Córdoba y los artistas Cristóbal, Ortega y Serrano. Asimismo, el catálogo de Arte Norte y Sur incluye entre los artistas de Estampa Popular de Vizcaya al pintor Valentín Ruiz Morquecho ${ }^{12}$. Este carácter abierto de colaboración demostraba una evidente realidad de movilización y cooperación entre artistas e intelectuales acomunados por el mismo espíritu de lucha.

\section{Una realidad enjuiciada}

El contexto social y económico de la industrialización y su incidencia en el paisaje urbano resultan referentes fundamentales para comprender la obra de Estampa Popular de Vizcaya. La elección de los temas por parte de los artistas respondía a su voluntad de plasmar la realidad que

\footnotetext{
La única investigación focalizada en el núcleo vasco ha sido "Estampa Popular de Vizcaya. El realismo social de los años 60 en el País Vasco", obra de investigación inédita de Valeria García-Landarte desarrollada entre 2003 y 2004. Derivado de este estudio es un artículo, de igual título, publicado en 2006 en Ondare. Cuadernos de Artes Plásticas y Monumentales (n. ${ }^{\circ}$ 25, pp. 393-401). Asimismo, Leire Macazaga ha dedicado un importante capítulo de su tesis doctoral "Grabadores vascos de las décadas de los 60 y 70" (defendida en 2013) al análisis del núcleo vizcaíno.

${ }^{9}$ Ibarrola en Guasch, 1985: 293.

10 Angulo, 1978: 65-66 y de Nicolás en VV.AA, 2000: p. 32.

11 El nombre de Morquecho no se menciona en el catálogo de dicha exposición. Sin embargo, sí aparece en las reseñas periodísticas sobre la muestra (véase A.R. "Expresionismo y realismo artístico. Conferencia de Antonio G. Pericás en las Salas Municipales de Arte”. En La Voz de España, San Sebastián, 10-III-1962: 9).

12 Morquecho nació en Bilbao en 1912. Comenzó como artista autodidacta y posteriormente se formó en Madrid y París. En 1951 participó en la I Bienal Hispanoamericana de Arte con la obra "Puerto Vasco". Fue miembro fundador de la Agrupación de Acuarelistas Vascos y fue incluido en el catálogo de la LXXV exposición de dicha agrupación entre "los doce apóstoles de la acuarela vasca" (Marrodán, 1988: 35).
} 
se vivía en España, con especial sensibilidad por la situación de la clase trabajadora, derivada de una experiencia directa de la problemática: los tres artistas provenían de ambientes familiares comprometidos con la izquierda y el mundo obrero. “¿No pedíais realismo al arte? ¿No solicitabais su hondo testimonio? ¿No queríais que los artistas estuvieran presentes en la elaboración de nuestra esperanza? Pues ahí los tenéis, ungiendo con pinceles y con gritos de tierra para que se tracen las coordenadas de nuestra realidad"13, exclamaba el poeta Vidal de Nicolás desde las páginas del catálogo de la exposición en San Sebastián.

Fue precisamente la defensa de los derechos de la clase trabajadora la causa de la corta existencia del grupo: Estampa Popular de Vizcaya vio truncada su actividad en 1962 cuando Ibarrola y Dapena fueron detenidos y acusados de militancia comunista, de "actividades subversivas" y de "participar en acciones cuyo fin era cambiar por la violencia el Régimen legal establecido en nuestro país"14. Tras ser encarcelados, se les sometió a un consejo de guerra por difundir propaganda clandestina y ayudar económicamente a los huelguistas de Euskadi y a los mineros asturianos ${ }^{15}$.

Una vez en libertad en 1965, los artistas continuaron trabajando de forma asidua con el grabado, aunque éste ya no fue el fundamento cohesionador o identitario del grupo. En estos años volvieron a cobrar una enorme importancia las exposiciones por los pueblos y, como señala García-Landarte ${ }^{16}$, es en este momento de transformación y crecimiento cuando la figura de Sol Panera cobra un papel fundamental. Sin ser miembro del grupo, Panera se constituyó como heredera de los presupuestos que habían guiado la actividad de Estampa Popular de Vizcaya. Aprendió a grabar con Dapena y se sumó a las exposiciones y actividades organizadas en colaboración con las asociaciones de vecinos cuando su maestra e Ibarrola salieron de la cárcel ${ }^{17}$.

\section{Las estampas: arte comprometido, arte vivido}

La comunión de ideas tanto en cuestiones ideológicas como en la práctica artística nunca implicó uniformidad de estilo para Estampa Popular de Vizcaya. En este sentido, los artistas participaban de la filosofía que alentó a la red Estampa Popular, donde las obras de cada integrante son perfectamente diferenciables, al contrario de lo que ocurría en el Equipo 57, en el que habían tomado parte previamente algunos de los artistas que se integraron en la red ${ }^{18}$.

Dentro de estas divergencias estilísticas, el caso de Dionisio Blanco resulta especialmente particular. Su experiencia personal y su fuerte conciencia de clase marcaron profundamente su obra. Sin embargo, a pesar de sus posiciones ideológicas muy próximas al comunismo, no participó de la dureza que caracteriza el trabajo de Dapena e Ibarrola. Es cierto que su actividad quedó truncada debido a sus condiciones físicas (una desafortunada caída desde un andamio en 1949 lesionó su columna), y sólo realizó un grabado, más concretamente un linograbado (fíg. 1), del cual probablemente sólo se estamparon tres pruebas ${ }^{19}$, de las que hemos conseguido localizar una perteneciente a una colección privada en Bilbao. No obstante, en esta obra se observan claramente los parámetros estéticos y formales que caracterizan el resto de su producción: el artista

13 De Nicolás/Giménez Pericás, 1962: s.p.

14 “Agitadores comunistas juzgados en consejo de guerra". En $A B C$, 22-IX-1962: 15.

15 Dapena, 1978: 112.

16 García-Landarte, 2006: 400.

17 Sol Panera expone brevemente el espíritu de este tipo de actividades en Gandía, 1996: 109.

18 Agustín Ibarrola y José Duarte, ambos miembros del Equipo 57, participaron en Estampa Popular de Vizcaya y de Córdoba respectivamente. Ibarrola cuenta cómo cuando Ortega le enseñó a grabar en París, él ya realizaba murales de arte testimonial (cuyo lenguaje y temática trasladaría después al papel) paralelamente a su actividad en el Equipo 57 (Angulo, 1978: 117). El desarrollo simultáneo de un arte abstracto por un lado y figurativo por el otro resultaba absolutamente natural, sobre todo si tenemos en cuenta que tanto el Equipo 57 como Estampa Popular compartían el objetivo de transformar la sociedad a través del arte (De Haro, 2010: 174 y 175).

19 Olga Seco en entrevista con la autora de este artículo, Bilbao, 27 de agosto 2014. 
acuña con delicadeza y meticulosidad la forma de sus figuras, personajes sin rostro pero de una gestualidad sumamente expresiva. La suavidad de la línea curva y el equilibrio de contrastes humanizan el dramatismo de la escena: la mujer embarazada sujeta simbólicamente la mano del preso sobre su vientre, una promesa de futuro.

Por su parte, Dapena, que también vivió precozmente en su familia la conflictividad política y social de la época, presenta una obra gráfica de gran ímpetu y fuerza expresiva, con una particular pátina nostálgica en su construcción formal. Se desconoce la cantidad exacta de ejemplares de los que constaba cada tirada, si bien sabemos que la artista solía realizar tiradas de entre 30 y 50 ejemplares ${ }^{20}$. Se conservan, además, matrices de algunas de sus estampas, lo cual enriquece enormemente el estudio de sus obras. La mayoría de sus grabados se encuentran en colecciones privadas, aunque en la actualidad también es posible observar en el Museo Reina Sofía de Madrid algunas de las nuevas estampaciones que se llevaron a cabo para la muestra sobre Estampa Popular celebrada en el IVAM en 1996.

Dapena transmite el efecto de realidad testimonial que caracteriza la mirada fotográfica y la pose, y su manera de acercarse al sujeto representado, junto al tamaño generalmente más bien reducido de las estampas, les confiere un cariz de cercanía que atrae al espectador. Sus composiciones son fotografías reinterpretadas de segalaris (segadores), arrantzales (pescadores), mineros o mujeres presas, de cuyas figuras se enfatizan las características más sobresalientes. A menudo, el punto de partida para sus composiciones consistía en salir con la cámara réflex a tomar fotos ${ }^{21}$ de los pescadores o las gentes que se reunían en los bares, gentes anónimas que más tarde se tornaban en protagonistas de sus grabados. En ellos se deja rastro de la transferencia entre los medios y el diálogo estético entre ambos: a través de la pose, la tensión del escorzo o la inmediatez de la captura instantánea en el efecto de corte, Dapena sitúa al espectador de su estampa en el lugar del fotógrafo, dirigiéndole su mirada.

Si bien muchos de sus personajes se muestran en actitudes tranquilas o estáticas, la expresividad corporal produce un gran desasosiego, pues refleja una realidad de pobreza difícil de confrontar. En Familia la desnudez del niño en primer plano y la tristeza de la mirada que proyecta la madre embarazada constituyen los límites de una composición que parece multiplicarse al infinito. Es impactante la economía de trazos con los que Dapena construye la mirada de los niños, sobre todo la de las niñas que encaran al espectador en una pose claramente fotográfica (fig. 2). Asimismo, su compromiso ideológico dio lugar a una galería iconográfica a partir de fotografías o postales dedicada a grandes figuras del comunismo y la lucha social, como Ernesto "Che" Guevara, Máximo Gorki, Salvador Allende o Vladimir Ilich Lenin.

\footnotetext{
20 Macazaga, 2014: 438.

${ }^{21}$ Gaizka Villate, hijo de María Dapena, explicaba la manera de trabajar de su madre en entrevista con la autora de este artículo, Valle de Mena, 25 de agosto 2014.
} 


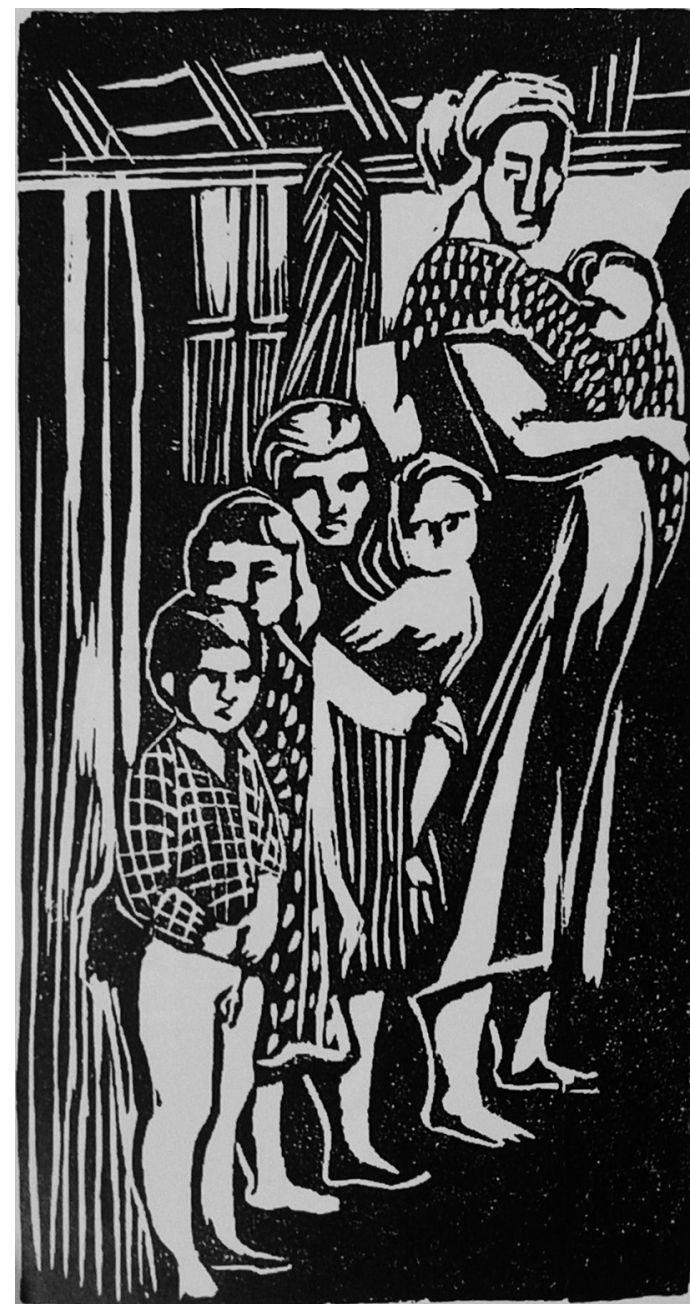

Fig. 2. María Dapena, Familia, s.f., linograbado.

Sin embargo, no todos los grabados de Dapena parten de una fotografía $\mathrm{y}$, desde luego, en ningún caso tratan de traducir el lenguaje tonal de ésta, pues, por lo general, sus composiciones se resuelven en fuertes y expresivos contrastes. En algunas estampas, como $\mathrm{Al}$ tiempo del guerrear (fig. 3), la artista imprime un enorme dinamismo a la acción mediante figuras agitadas, conmocionadas, recortadas sobre el fondo con formas angulosas y desencajadas. Así es como Dapena ve y representa las dos Españas enfrentadas de las que habla Blas de Otero en su poema "La va buscando".

Las obras que reflejan su experiencia en la cárcel conforman una parte fundamental de la obra pictórica y gráfica de la artista. Estas estampas nos transmiten la profunda tristeza de las presas (fig. 4) y la angustia de los presos vigilados mientras son trasladados en tren (figs. 5 y 6): aquí la expresividad no radica sólo en las actitudes y los intensos contrastes lumínicos, sino también en las violentas diagonales que fragmentan el espacio del vagón y lo constriñen, subrayando el drama del sufrimiento ante la falta de libertad. Para esta dramática escena Dapena utiliza una plancha con una superficie reticular, cuya textura recrea el efecto opresivo del encierro y genera una sensación inquietante, pues las personas acaban confundiéndose con los objetos en una expresión deshumanizadora que refleja la suerte que esperaba a aquellos que se enfrentaban al régimen, personificado en la figura del guardia civil.

En cuanto a Agustín Ibarrola, nacido también en el seno de una familia obrera, se inició en el arte del grabado con una importante obra pictórica y labor de investigación plástica a sus espaldas. Respecto a las de sus dos compañeros, las tiradas de Ibarrola eran más altas, de 500 ejemplares. Se trata, sin embargo, de un número orientativo, dado que la precariedad de medios y la situación política y social del momento no permitían un control real de las ediciones, máxime tratándose de tiradas tan elevadas. En su caso, el propio autor solía numerar, titular y firmar a bolígrafo las estampas, que ahora pueden hallarse en diversos museos, bibliotecas o galerías, como el Museo Reina Sofía, el Museo de Bellas Artes de Bilbao, la Colección UC de Arte Gráfico, la Biblioteca de la Diputación Foral de Bizkaia y librerías anticuarias o galerías de grabado de Bilbao.

Sus grabados manifiestan un rico bagaje artístico que, al igual que ocurre en su obra pictórica, aflora en la sapiente construcción de las formas, los volúmenes y el espacio plástico. Los componentes fundamentales de la gramática visual de Ibarrola son las líneas diagonales, siempre audazmente utilizadas para desestabilizar la ortogonalidad de la composición, activar el espacio y estructurar las figuras. Se puede hablar de una abstracción absolutamente personal en la forma de romper con la perspectiva tradicional, dislocándola y desvirtuándola. No existe un punto de fuga, pero el artista es capaz de crear un foco de atención a partir del cual va construyendo y equilibrando el resto de la composición. En esta concepción espacial juega un papel primordial su conocimiento del muralismo mexicano, en especial de Siqueiros, del cual le impresionan los 


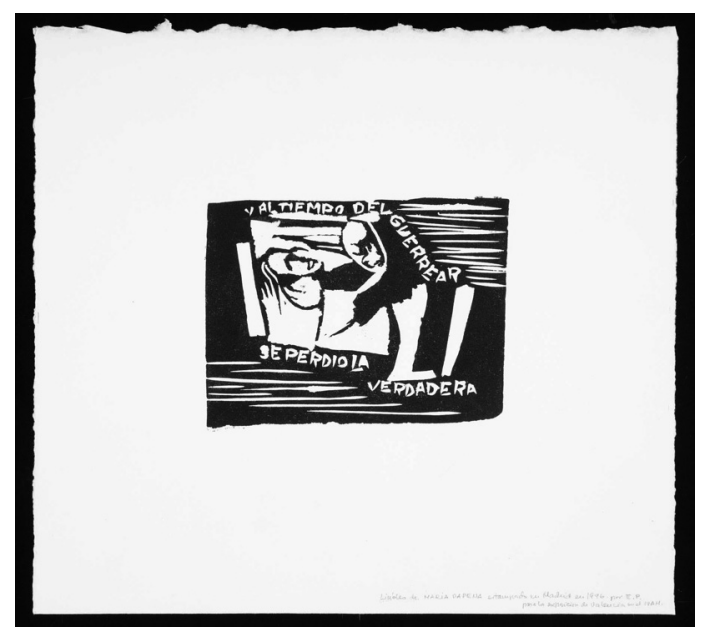

Fig. 3. María Dapena, Y al tiempo de guerrear..., prueba estampada en 1996 con motivo de la exposición Estampa Popular en el IVAM, linograbado, $120 \times 160 \mathrm{~mm} /$ papel, $335 \times 310 \mathrm{~mm}$.

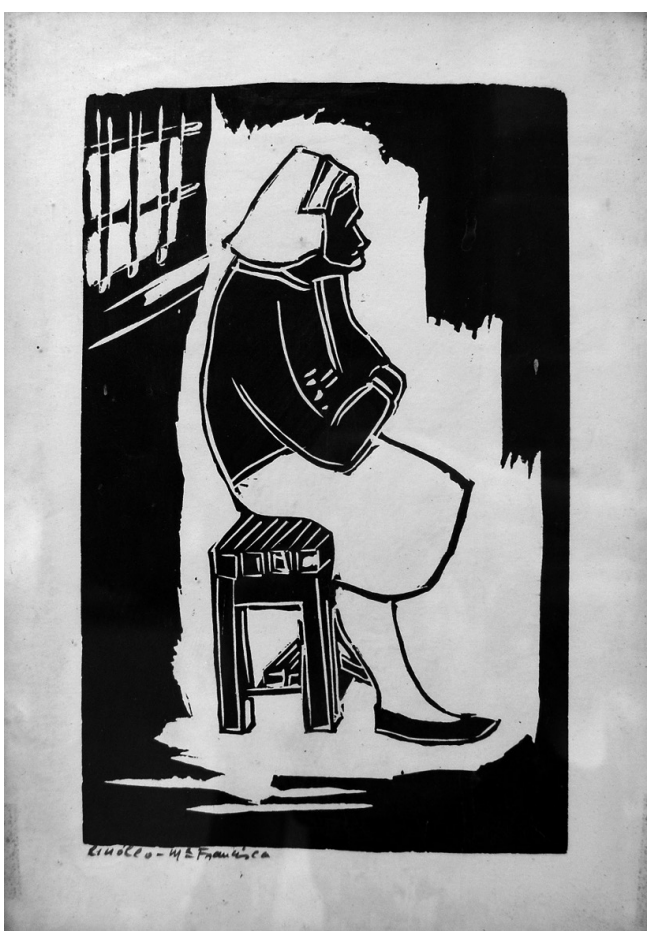

Fig. 4. María Dapena, Sin título, s.f., linograbado, $245 \times 157 \mathrm{~mm} /$ papel, $310 \times 220 \mathrm{~mm}$.



Fig. 6. María Dapena, Sin título, s.f., plancha de linóleo, $269 \times 150 \mathrm{~mm}$.
Fig. 5. María Dapena, Sin título, s.f., linograbado, $269 \times 150 \mathrm{~mm} /$ papel, $311 \times 211 \mathrm{~mm}$.

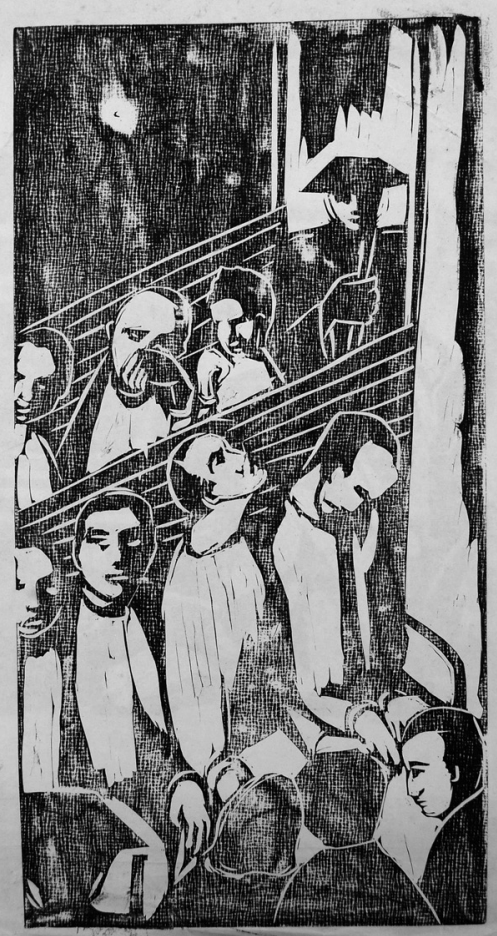

Archivo Español de Arte, vol. XC, n. ${ }^{\circ}$ 358, pp. 155-170, abril-junio 2017

ISSN: 0004-0428, eISSN: 1988-8511, doi: 10.3989/aearte.2017.10 


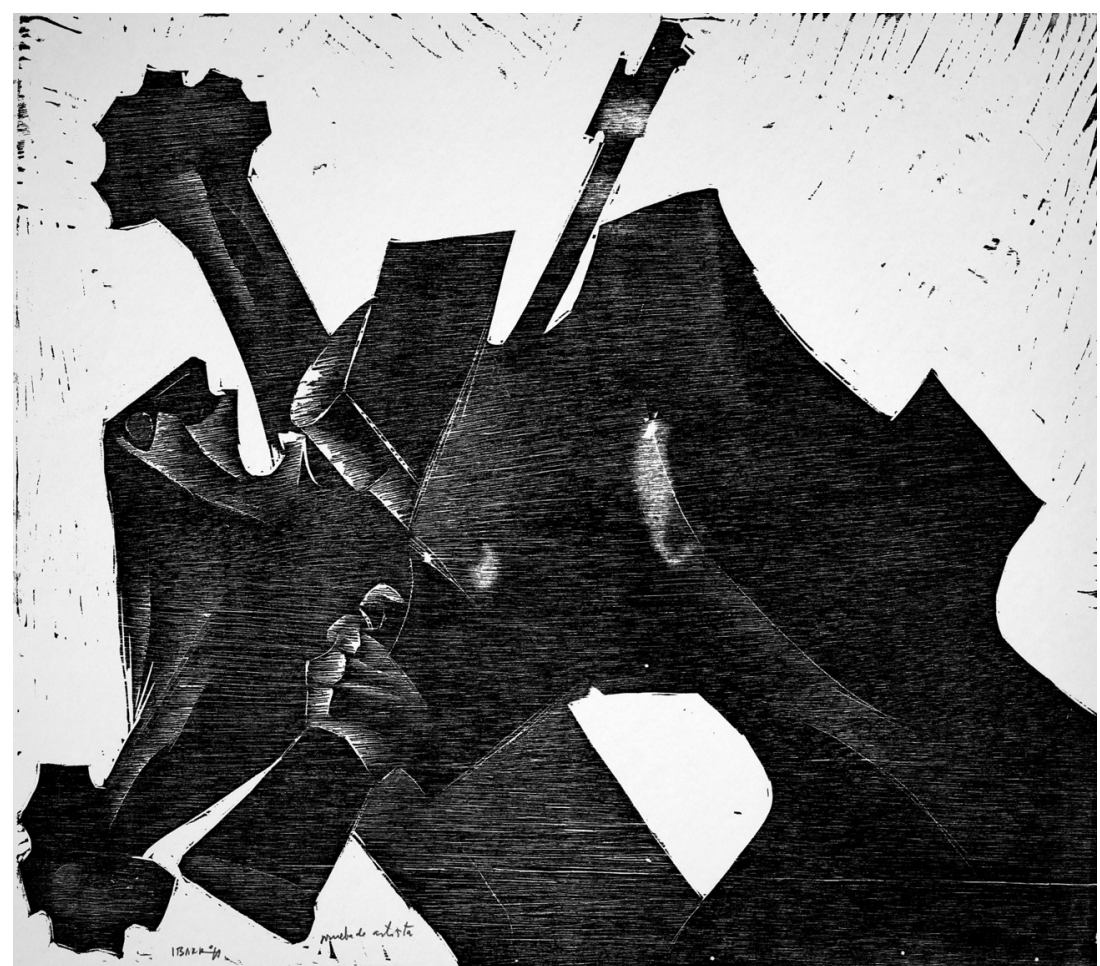

Fig. 7. Agustín Ibarrola, Sin título, s.f., grabado en madera a la fibra.

escorzos, los juegos de perspectiva y la articulación de las formas ${ }^{22}$. La composición se ve además reforzada por un cuidado y compensado juego de volúmenes. La representación del entorno vital de la sociedad vasca también merece una atención especial. El paisaje fabril en el que se mueven los personajes está a menudo caracterizado por chimeneas altas y amenazantes, pasarelas por las que se desplazan masas de trabajadores o figuras que se manifiestan mostrando pancartas. Sin duda, una de las grandes audacias plásticas de Ibarrola es el modo en que piensa y organiza las representaciones humanas y espaciales, donde se hace patente su dominio del geometrismo, componente sustancial, como es sabido, del Equipo 57 en el que participó.

La construcción de figuras a través de perfiles, como si de formas recortadas se tratase, y la superposición de las mismas le permiten crear una suerte de profundidad sin matices de claroscuro. Este recurso plástico genera un efecto tridimensional, una ilusión espacial expresiva donde se evidencia su habilidad para sacar todo el potencial de la madera, de sus tendones, vetas y nudos. A menudo, sus personajes se construyen como esculturas monumentales, volúmenes que se proyectan y retraen dejando en una confrontación violenta un rastro de brillo casi metálico, evocador del bronce, que recorre y recorta los planos, las formas, incluso los pliegues apuntados de las ropas (fig. 7). En este violento ataque de un guardia civil a una mujer, la fuerza visual se enfatiza gracias a la utilización reductora de dos planos donde se impone el vacío como espacio. La supresión de lo anecdótico hace que el espectador se centre en la lucha desigual, en el valor de la resistencia que desvela ese cuerpo a cuerpo sin posibilidad de triunfo. Ibarrola universaliza la representación, la arranca de la realidad del País Vasco y la proyecta sobre el resto del país ${ }^{23}$.

22 Agirre/Garmendia/Martínez, 1991: 16.

${ }^{23} \mathrm{Su}$ compromiso contra la represión y la dictadura, trascendía los sucesos ocurridos en Euskadi y sus estampas también se ocupan de acontecimientos como la Caputxinada de Sarriá en 1966 o la agresión de Estados Unidos a Vietnam. 


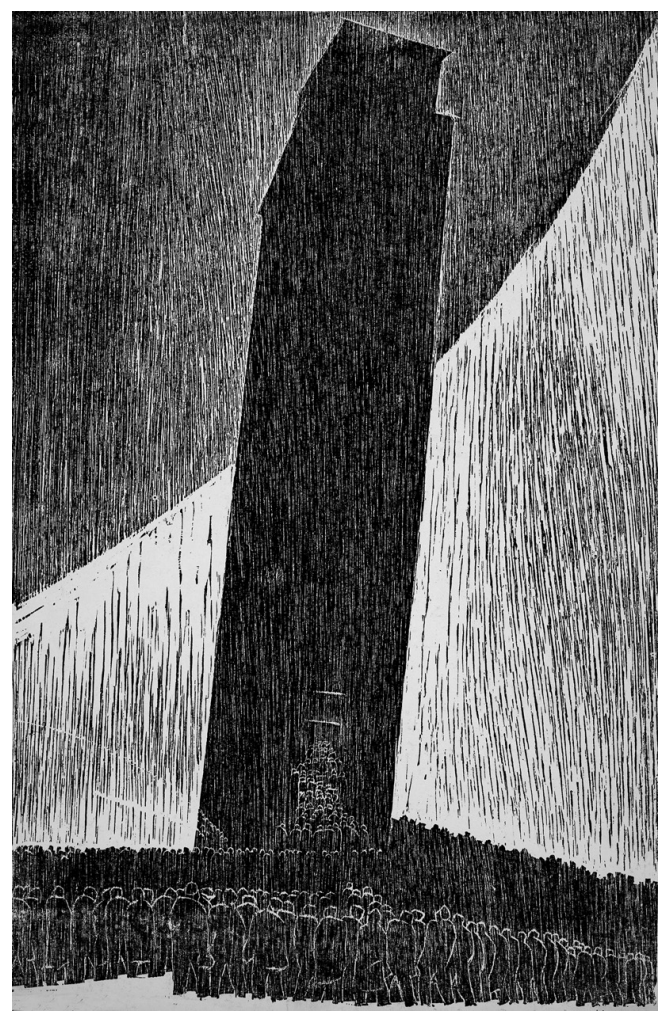

Fig. 8. Agustín Ibarrola, Magistratura de Trabajo contra los obreros de Bandas, s.f., grabado en madera a la fibra.

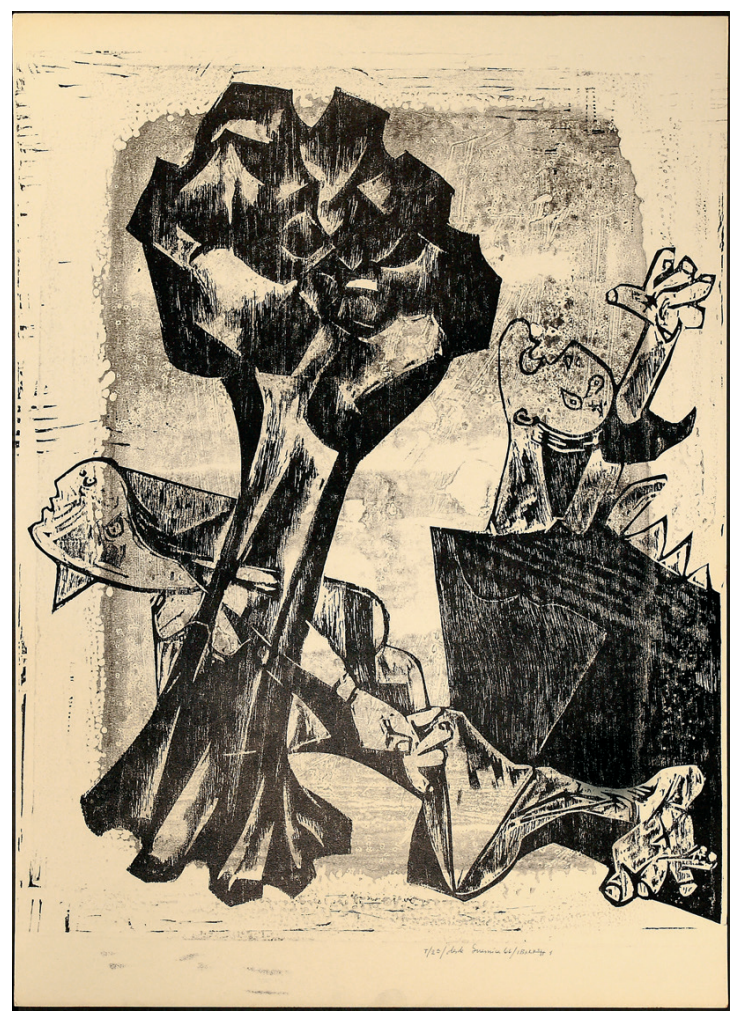

Fig. 9. Agustín Ibarrola, Desde Guernica, s.f., grabado en madera a la fibra, $635 \times 496 \mathrm{~mm} /$ papel, $701 \times 499 \mathrm{~mm}$

Asimismo, las estampas de Ibarrola plasman, muchas veces, una crónica de los acontecimientos de la historia reciente centrada en el País Vasco. La serie Paisajes de Euskadi, comenzada en 1960 , representaba, en sus propias palabras:

El paisaje real, el geográfico, el político, el social, el paisaje humano, la situación nacional [...]. Es el paisaje completo de toda la sociedad vasca. [...] Abunda la represión, las masas oprimidas y la violencia del régimen. Son los signos que evidencian la situación que vivíamos; son los rasgos casi exclusivos de una época ${ }^{24}$.

Los rasgos de la época que se recogen en los grabados de Ibarrola están jalonados de acontecimientos de protesta de gran trascendencia en Euskadi. Tal es el caso de la estampa que representa la famosa "Huelga de Bandas" (1966-67), donde la masa de obreros se concentra al pie del Rascacielos Bailén en Bilbao, entonces sede de la Magistratura de Trabajo (fig. 8); o La Basconia, dedicada a las protestas que tuvieron lugar en Basauri en 1966 por los trabajadores de la Basconia S.A. en contra de las bajas retribuciones salariales. Es esta misma razón de denuncia y testimonio la que lleva a Ibarrola a hablar de "los nuevos Guernicas" 25 que hay en Euskadi e introducir en sus grabados citas visuales del Guernica de Picasso (fig. 9).

24 Angulo, 1978: 230.

25 Angulo, 1978: 202. 


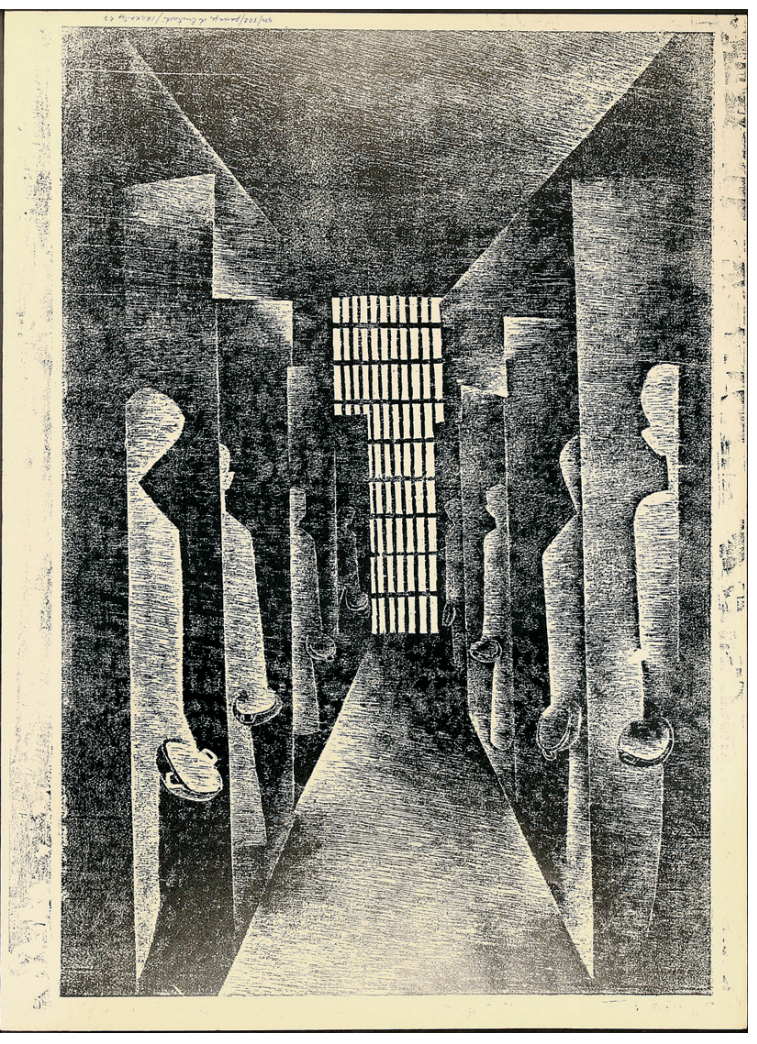

Fig. 10. Agustín Ibarrola, Paisajes de Euskadi, s.f., grabado en madera a la fibra, $665 \times 445 \mathrm{~mm} /$ papel, $701 \times 511 \mathrm{~mm}$.

$\mathrm{Al}$ dominio de la técnica, la incorporación de la imaginería de lucha y el compromiso político, hay que sumar la vivencia personal de lo representado. Esto se aprecia de una manera todavía más directa en las imágenes que expresan su experiencia en prisión. Si bien en consonancia con el resto de su obra, el drama personal queda en segundo plano, trasciende su individualidad para alzarse en una feroz denuncia de la situación de todos los presos (fig. 10).

La alienante realidad vivida se recoge mediante una estetización geométrica y unos efectos dramáticos cuya potencia visual es sobrecogedora. El lenguaje de contrastes lumínicos, formas y líneas imprimen una dinámica a sus personajes, que se convierten en poderosos volúmenes, en moles reiterativas con enorme efecto multiplicador. Éstos no sólo se activan y se mueven, sino que incitan al espectador a la acción, que es precisamente el objetivo que perseguía Estampa Popular. No obstante, en la recepción de las obras no sólo es fundamental el público, sino también las formas de distribución.

Como el resto del arte producido por la red, los grabados de Estampa Popular de Vizcaya responden a la idea de "arte popular" - materiales baratos combinados con la utilización de un lenguaje expresivo de comprensión inmediata-, pero ante todo se trataba de un arte de urgencia y denuncia social. No se trataba de un arte panfletario puesto que los artistas no siguieron ningún tipo de consigna partidista ${ }^{26}$. Esta distinción entre la militancia individual — los tres miembros del grupo militaron en el Partido Comunista de Euskadi, si bien Blanco ingresó más tarde_- y la mentalidad que guiaba a la red resulta de un gran interés puesto que evidencia que el destinatario de la obra trascendía las siglas del partido. Sin embargo, es enormemente complicado saber qué tipo de público se relacionaba con los grabados o estaba interesado en adquirirlos, puesto que apenas tenemos datos acerca de los visitantes de las exposiciones o los compradores de las estampas, que los artistas vendían a precios irrisorios ${ }^{27}$ cuando no las regalaban.

No obstante, el alcance de la obra trascendía con creces el "sistema del arte" del momento, pues existían otras maneras de que el público accediera a ellas. Ibarrola, por ejemplo, siguió grabando durante su encarcelamiento, y con las planchas que conseguía sacar de la prisión los mismos obreros realizaban las tiradas "como podían" a pesar de no poseer conocimientos de estampación. Las pruebas eran luego vendidas por los trabajadores y estudiantes como un medio para apoyar el movimiento huelguístico y de protesta $^{28}$.

${ }^{26}$ Acerca de la relación entre Estampa Popular y el PCE véase de Haro, 2010: 149, 150, 346 y 365; y Angulo, 1978: 231.

${ }^{27}$ Las personas consultadas para este trabajo concuerdan en que el precio solía ser de 100 pesetas.

28 Agustín Ibarrola en entrevista con la autora de este artículo, Oma, 9 de agosto 2014. 
Los grabados eran objeto de interés por parte de la intelectualidad española de los años $1960^{29}$, pero también se constituían como instrumento de cohesión y construcción de la conciencia de clase entre los trabajadores que contribuían a su materialización y difusión. Su significado radicaba tanto en el elemento visual, es decir, en el sujeto representado en cuanto imagen en la que reconocerse, como en su carácter de objeto material que se movía en un circuito de respaldo a la lucha. Por último, para las personas que adquirían las estampas y no formaban parte de la clase obrera, representaba un instrumento de solidaridad, por ser una expresión de testimonio y denuncia, además de una señal de apreciación en su dimensión estética en tanto que objeto artístico.

\section{La materialidad como registro y testimonio}

En la fuerza de la imaginería de las obras se plasmaban la realidad de la dictadura, la lucha y la resistencia popular. Todo ello quedó además registrado en la fisicidad de las estampas, pues las precarias condiciones que imponía la clandestinidad han dejado su huella en las obras. Está claro que el análisis de las imágenes en su doble valencia estética y documental es fundamental para una mejor comprensión de la obra y apreciación de la capacidad creativa del artista. Sin embargo, el estudio de la materialidad de la obra ofrece además su consideración como artefacto cultural capaz de desvelar las prácticas y los usos en el devenir de su existencia.

En este sentido, el estudio de la técnica empleada por Ibarrola y Dapena resulta sumamente revelador, pues manifiesta un fuerte sentido de urgencia e inmediatez, significando al mismo tiempo la recuperación de conceptos y lenguajes populares, alejados de consignas académicas. A pesar de que algunos artistas de Estampa Popular utilizaron técnicas de grabado calcográfico, la mayoría de ellos, como hicieron los artistas vascos, se decantaron por el empleo sistemático de la madera y el linóleo. Esto se debió tanto a una cuestión de índole formal y estética como a una razón práctica y económica de disponibilidad y accesibilidad de estos materiales. El procedimiento que normalmente seguían los grabadores de Estampa Popular era el más primitivo, el grabado en relieve trabajado con gubias, cuchillas, punzones o escoplos, es decir, un instrumental constituido por herramientas comunes en la ebanistería y la carpintería y, por tanto, fácilmente accesible y barato. Para los soportes, como cuenta el mismo Ibarrola, se utilizaban maderas contrachapadas o linóleos, y la tinta no se compraba en ninguna tienda, sino que se conseguía mediante amigos que tuvieran acceso a una imprenta ${ }^{30}$.

En cuanto al papel, generalmente utilizaron papel de algodón satinado, similar al papel de cartulina. El satinado hace que el papel sea menos poroso, por lo que absorbe menos tinta, lo que redunda en economía de materiales y tiempo pues la estampa tarda menos en secar. Por otro lado, la tersura del papel devuelve un efecto de nitidez brillante muy sugestivo. No obstante, dada la baja calidad del papel, su acidez ha contribuido a su temprano deterioro haciéndolo quebradizo y friable, al tiempo que lo amarillea. Asimismo, en algunas ocasiones, como en el caso de Dapena (fig. 11), la artista también empleó materiales elementales e improvisados como cartones recortados.

\footnotetext{
29 Antonio Giménez Pericás, Moreno Galván, Tomás Llorens, Valeriano Bozal o Vicente Aguilera Cerni mostraron su interés y escribieron sobre Estampa Popular, el realismo y el papel del artista en la sociedad ya durante los años 1960. De modo extremadamente somero podemos recordar "Despersonalización de arte y sociedad" aparecido en el n. ${ }^{\circ} 11$ de Acento Cultural (1961) y escrito por Antonio Giménez Pericás (quien hemos visto que se involucró en las dos exposiciones de Estampa Popular de Vizcaya); "El realismo social que pasa por Madrid" (1963) en Suma y sigue del arte contemporáneo (n. ${ }^{\circ}$ 3) firmado por Moreno Galván; "Realismo y arte comprometido" de Tomás Llorens, publicado en 1963 en Suma y Sigue del Arte Contemporáneo (n. ${ }^{\circ}$ 4); El realismo, entre el desarrollo y el subdesarrollo (1966) de Valeriano Bozal; o Iniciación al arte español de la postguerra (1970) de Aguilera Cerni. Para una mayor comprensión acerca de la relación entre estos intelectuales y los artistas véase el trabajo de Noemi de Haro, que ofrece una visión exhaustiva al respecto.

${ }^{30}$ Agustín Ibarrola en entrevista con la autora de este artículo, Oma, 9 de agosto 2014.
} 


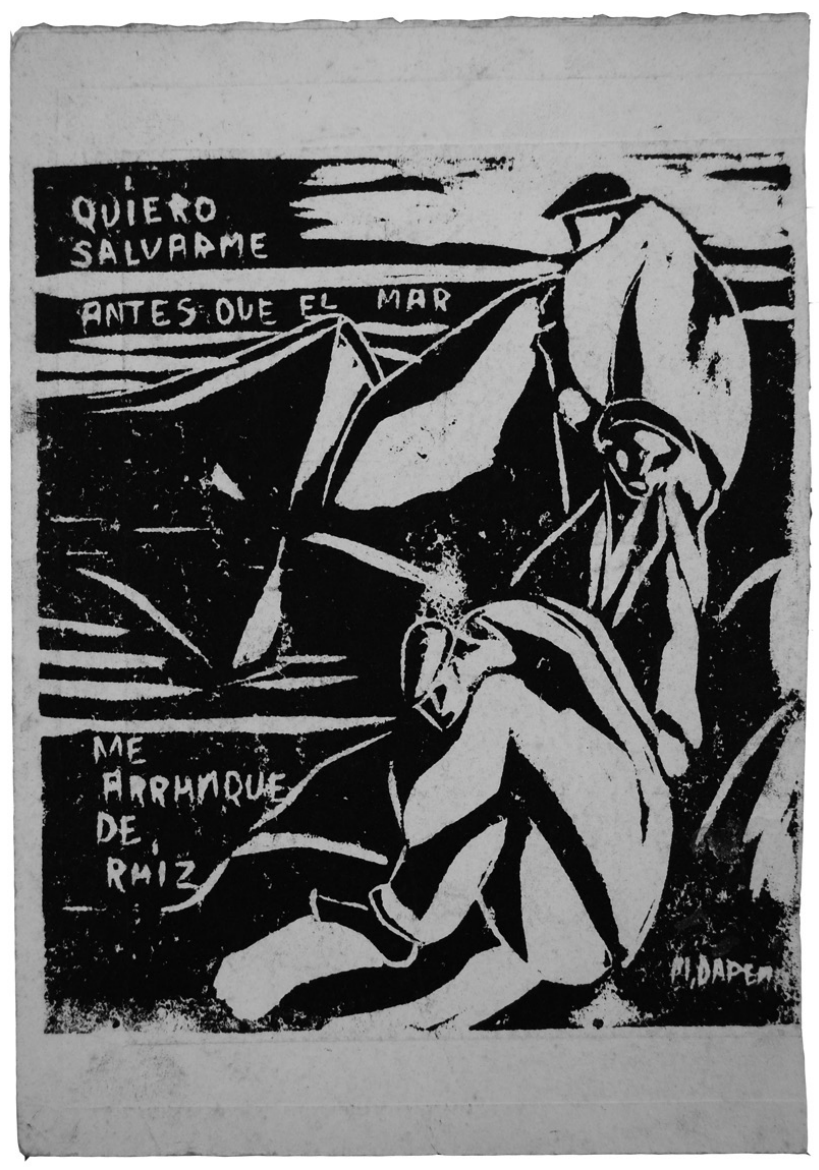

Fig. 11. María Dapena, Sin título, s.f., linograbado, $189 \times 159 \mathrm{~mm} /$ papel, $239 \times 165 \mathrm{~mm}$.
Las herramientas empleadas para estampar eran muy rudimentarias. Los artistas normalmente no utilizaban tórculos o prensas, y tampoco intentaron conseguir este tipo de maquinaria por temor a que fuese interpretado como un artefacto de propaganda subversiva; se estampaba manualmente, bien utilizando una cuchara o una madera, bien presionando con un rodillo por enci$\mathrm{ma}^{31}$. Sol Panera recuerda cómo en ocasiones llegaron incluso a valerse de un rodillo de máquina de escribir $^{32}$. La utilización de estos procedimientos tan rudimentarios ha dejado su huella en las estampas: resulta muy frecuente, por ejemplo, encontrar calvas porque al entintar no se ha calzado bien el soporte, desvaídos en el tono provocados por la mala calidad de la tinta, o grumos y coágulos causados porque el fluido estaba medio seco.

El efecto debido a un desigual entintado es un agente muy activo en el impacto visual de la composición, pero también en la consideración final de la estampa como obra de arte. Se trata de una materialidad descuidada ajena a la pulcritud de las ediciones de obra gráfica que se comercializaban en las galerías, y al mismo tiempo enormemente evocadora, pues en ella ha quedado registrada la realidad de dificultades y lucha en la que fueron creadas las obras. Basta contemplar el reverso de muchas de las estampas para comprobar la huella de cotidianeidad: manchas, rastros de humedad, marcas de cinta adhesiva y huellas dactilares nos devuelven la impronta de su utilización, de su razón de ser como instrumentos de denuncia.

Debido a este proceso de entintado tan precario, cada prueba se configura casi como una obra única (fig. 12). No significa esto que fuera intencionado pues, desde luego, no hay rastro del criterio comercial que regía la obra gráfica desde finales del siglo XIX en relación al control y extensión de las tiradas. Es éste otro aspecto que hay que tener en cuenta cuando se habla de obra gráfica en los años de la dictadura franquista: la regulación de las pruebas de estado, el bon à tirer - la prueba de estampación definitiva escogida por el artista como modelo de toda la tira$\mathrm{da}$ - y las pruebas de artista se encontraban en un estado bastante precario; en el caso de Estampa Popular de Vizcaya, como hemos podido comprobar, fueron inexistentes. En este sentido, las disimilitudes entre diferentes ejemplares podrían considerarse un ulterior elemento de resistencia ante las imposiciones elitistas del mercado y del degustador de estampas, ambos pertenecientes

31 Angulo, 1978: 119 y 230.

32 Sol Panera en entrevista con la autora de este artículo, Galería Aritza, Bilbao, 23 de julio 2014. 


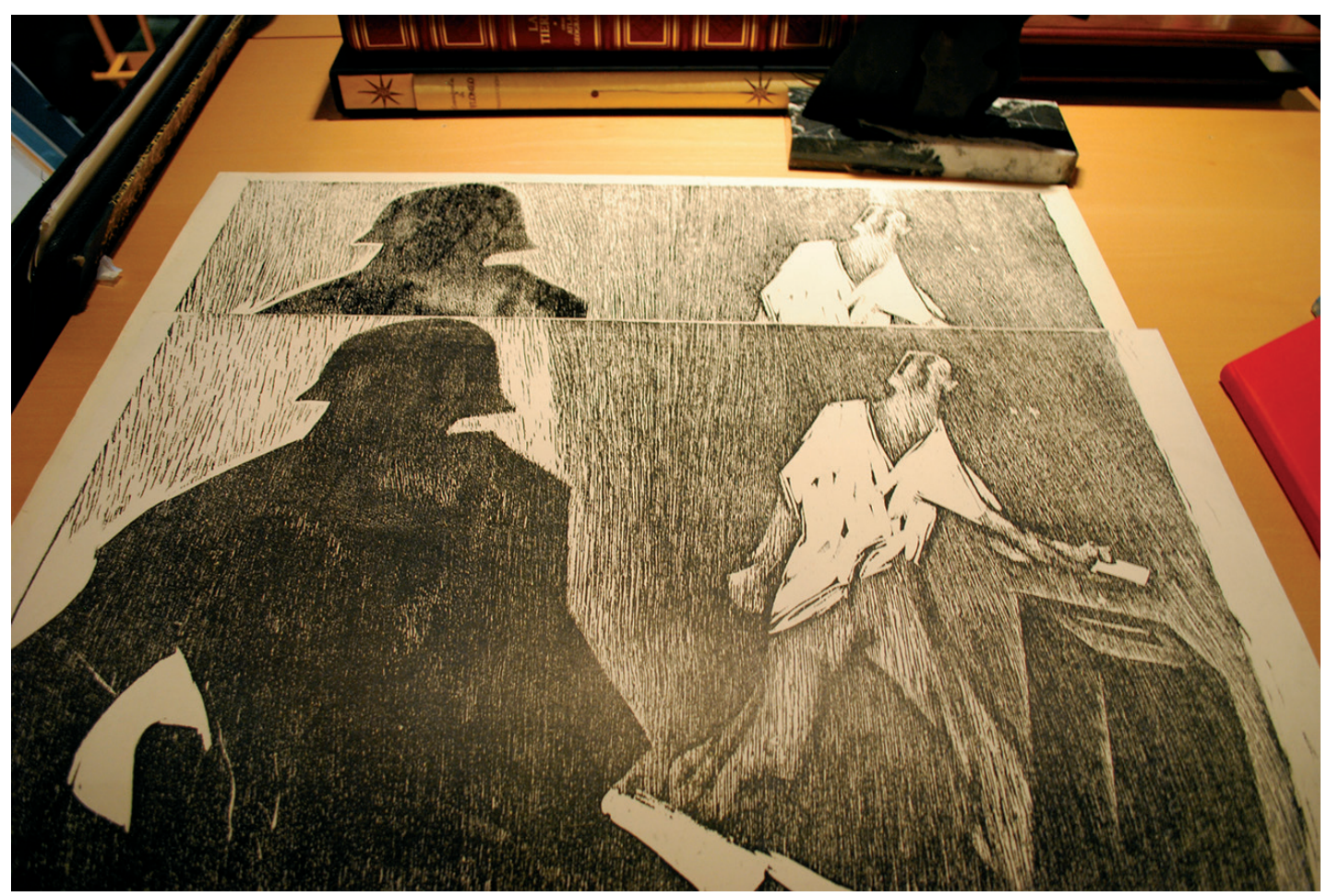

Fig. 12. Agustín Ibarrola, Los yanquis contra los pueblos, s.f., grabados en madera a la fibra, $485 \times 650 \mathrm{~mm} /$ papel, $505 \times 705 \mathrm{~mm}$.

a ese sector cuya apreciación de la obra gráfica se fundamentaba en la diferenciación del ejemplar por la numeración de la tirada y la adquisición de pruebas raras.

La capacidad del grabado para traducir de manera inmediata fuertes emociones, que llevaban al artista a enfrentarse a materiales vulgares como el contrachapado o el linóleo, hicieron de él un medio idóneo para comunicar vivencias dramáticas, difundir ideas y denunciar la brutalidad de la dictadura. La manera de grabar, en definitiva, era en sí misma una declaración de principios, era expresión de resistencia.

\section{La vida más allá de Estampa Popular de Vizcaya}

En este proceso exegético sobre las estampas desde el punto de vista de la materialidad, resulta necesario interrogarse sobre el recorrido vital de las obras hasta la actualidad. Para ello, es esencial pensar la obra en su doble condición de objeto del pasado, producto de la creación humana, sometido al mismo tiempo a los intereses del presente ${ }^{33}$.

Actualmente, la manera más accesible para contemplar la obra de Estampa Popular es en el ámbito del museo, ya sea en exposiciones temporales o como parte de la exposición permanente. En este sentido, es enormemente relevante que haya un espacio en un museo de referencia como el Museo Reina Sofía (sala 414) dedicado a Estampa Popular. Al otorgar visibilidad a esta red,

33 Vega, 2008: 229-234. 
se la reconoce como un agente importante de la actividad artística española del siglo XX. Este espacio resulta sin duda la culminación de un progresivo interés por recuperar la actividad de Estampa Popular que ha estado jalonado por la publicación de estudios que han contribuido a su puesta en valor ${ }^{34}$, provocando a su vez que determinadas instituciones culturales se hayan interesado por adquirir y conservar este patrimonio ${ }^{35}$.

La consecuencia inmediata de este proceso de recontextualización es que las estampas se ofrecen enmarcadas al visitante - reforzando su afinidad con la pintura- donde prevalece el criterio estético que busca hacer visualmente atractiva la obra. En este nuevo marco conceptual las obras resultan desactivadas y, como explica Carol Becker, "cuando la obra toma una postura social o política y refleja la situación de los tiempos, o es ignorada o cuando es aceptada, entonces es absorbida, es transformada en una mercancía, y su poder diluido" 36 . En el caso que nos ocupa, las estampas convertidas en un cuadro y colgadas en un museo de arte se relacionan con un público que generalmente no es consciente de que su ser se ha transformado inevitablemente. Lo que en su día circulaba por los derroteros de la clandestinidad, lo que era un "arte de la calle", es integrado en la oficialidad institucional, que potencia como carácter principal lo que antes no lo era.

Estos recorridos vitales de las obras plantean nuevos interrogantes y posibilidades de interpretación. El trabajo de rastreo revela situaciones paradójicas, como por ejemplo encontrarse pruebas de época en lugares inesperados de Bilbao, como puede ser el portal de un edificio de oficinas ${ }^{37}$. Su destino final hace todavía más evidente su dramático proceso de descontextualización y su transformación en elementos meramente "decorativos", en los que la función política y social ha quedado enmudecida. Esa misma mirada es la que prevalece también en las tiradas actuales, no sólo en lo que se refiere a su recepción pública sino también a su especificidad física.

El caso que mejor ilustra lo expuesto es la nueva estampación hecha ex profeso para la exposición sobre Estampa Popular celebrada en el IVAM en 1996. En esa ocasión algunos grabados de Dapena (fig. 3) se estamparon para incluirlos en la muestra. Para ello se eligió un papel de gramaje con barbas, lo que acentuaba la huella - registro de contacto directo y garantía de originalidad - y de tono muy blanco, que reforzaba el efecto de contraste con la intensidad oscura y densa de la tinta; la mancha se situó siguiendo los cánones actuales con amplios márgenes

${ }^{34}$ Como ya se ha mencionado, la fortuna crítica de Estampa Popular está indisolublemente ligada a la figura de intelectuales como Aguilera Cerni, Bozal, Llorens, Moreno Galván, o Giménez Pericás, que escribieron sobre Estampa Popular durante los años de actividad de esta red de artistas. Desde el fin de la dictadura, Estampa Popular también fue objeto de investigación, aunque se trata por lo general de estudios inéditos, focalizados en un determinado grupo, resultados normalmente de la vinculación entre el autor y el contexto local del núcleo artístico analizado (véase De Haro, 2010: 26). Por esta razón, se puede considerar que la primera investigación dedicada a Estampa Popular en su conjunto fue la tesis doctoral de Noemi de Haro del año 2010, publicada bajo el título Grabadores contra el franquismo. En su estudio, De Haro ofrece una visión amplia y rigurosa del conjunto de artistas y propone una relectura crítica de Estampa Popular considerando las interrelaciones, las dinámicas de grupo y las narraciones historiográficas a las que ha dado lugar esta red, distanciándose del paradigma y la interpretación canónica aceptada hasta ese momento.

35 A partir de la década de 1990 se han organizado diferentes muestras que revelan un interés creciente sobre el tema. En 1996, se presentó la exposición Estampa Popular en el Centro Julio González del IVAM. Se trataba de la primera y, hasta el momento, única exposición que ofrecía una vasta panorámica coral del movimiento, siendo su principal mérito aunar las obras y voces de los integrantes y las personas relacionadas con los diferentes grupos (exceptuando Galicia). A comienzos de los 2000 se organizaron sendas muestras dedicadas a Estampa Popular de Madrid (Estampa Popular de Madrid. Arte y política 1959-1976) y Barcelona (Cap una altra realitat. El context d'Estampa Popular) en los años 2005 y 2006 respectivamente. Un año más tarde, en 2007, la Universidad de Cantabria adquirió obras de Estampa Popular y organizó la exposición El movimiento Estampa Popular en la Colección UC de Arte Gráfico. En 2010 el Museo Reina Sofía también incluyó en su colección grabados de Estampa Popular y, en 2011, propuso la visita comentada Estampa popular e imagen crítica en España.

36 "When work does take a political or social stance and does reflect the temper of the times, it is either ignored or, when accepted, then absorbed, transformed into a commodity, its power diluted" (Becker, Carol, "Private Fantasies Shape Public Events: And Public Events Invade and Shape Our Dreams". En http://www.thefileroom.org/publication/ becker.html [14-VIII-2015]).

37 Agradezco a Valeria García-Landarte que me señalara la existencia de estos grabados. 
alrededor. Además de acomodarse al gusto y las prácticas de nuestros días, la limpieza y pulcritud de la estampación refuerzan la transformación de la obra en pieza de museo, cuya estetización $^{38}$ crea una brecha entre lo que fue la intención original de la obra y la nueva tirada. El papel empleado, su gramaje y calidad, invisibiliza la falta de recursos que sufrieron los artistas, y su cuidada estampación, la precariedad con la que se hicieron las pruebas. El mismo tono del papel dista enormemente del aspecto de las pruebas antiguas, cuyo color agarbanzado, tirando a amarillento por la acidificación del papel, establece una relación tonal que no es la primigenia pero sí más acorde con el tiempo transcurrido, fruto de esa sordina que pone el paso del tiempo a la materia.

Por otro lado, la oferta de material de calidad permite que la obra de arte esté abierta a nuevas experiencias y reinterpretaciones estéticas, como la indagación del potencial plástico de las estampas con el empleo, en ocasiones, de tintas de diferentes colores que dan una nueva vida a la obra (no obstante, por lo general, se ha mantenido en las nuevas tiradas el color negro). La tinta utilizada ya no es tinta de imprenta porque en la actualidad existe una amplia gama de tintas de excelente calidad para estampar con fines exclusivamente artísticos y cuyos componentes, combinados con la porosidad del papel - de mayor capacidad de absorción-, producen un efecto denso, aterciopelado y mate que no tienen las pruebas antiguas. Por último, el entintado homogéneo y la pulcritud del acabado confieren a la estampa una apariencia "solemne", digna de ser colgada en el "cubo blanco" del museo.

Las estampas, que en su ser llevan impresos los momentos de dificultades y penurias en las que nacieron, nos manifiestan en su imaginería la violencia de la realidad social en la que fueron creadas, convertidas en auténticos elementos de acción. Entender su razón de ser en la tesitura social y política en la que nacieron y su papel en un proceso de lucha que aunaba artistas, poetas y literatos, nos permite comprender no sólo su interacción con el público al que iban dirigidas en aquel momento, sino también con el actual. A la postre, en cada una de las pruebas de los años 1960 el pasado se nos hace presente y nos obliga a relacionarnos con una época que no es tan lejana en el tiempo pero que queda en parte invisibilizada por las ediciones modernas. Por otro lado, también es cierto que estas ediciones modernas son los mejores dispositivos para revalorizar las estampas, cuya escasez pone a su vez en valor que se lleve a cabo una nueva estampación. Resulta necesario, por tanto, interrogarnos acerca de nuestra posición a la hora de abordar el estudio de estas obras y tomar conciencia, asimismo, de las formas en las que hoy en día se reconfigura nuestra experiencia de las mismas.

\section{BIBLIOGRAFÍA}

A.R. "Expresionismo y realismo artístico. Conferencia de Antonio G. Pericás en las Salas Municipales de Arte". En $L a$ Voz de España, San Sebastián, 10-III-1962.

Agirre, Imanol/Garmendia, Carmen/Martínez, Carlos (1991): Ibarrola 1948-1991, San Sebastián: Museo de San Telmo. Aguilera Cerni, Vicente (1970): Iniciación al arte español de la postguerra, Barcelona: Península.

Angulo, Javier (1978): Ibarrola, ¿Un pintor maldito?, San Sebastián: L. Haranburu.

Barrena, Clemente/Leyva, Antonio (2006): Estampa Popular de Madrid. Arte y política 1959-1976, Madrid: Museo Municipal de Arte Contemporáneo de Madrid.

38 Puede resultar redundante hablar de estetización de las estampas cuando, en cuanto imágenes y obras de arte, tienen en sí mismas una indudable condición estética. Sin embargo, en palabras de Gerard Vilar, "no es cierto que toda imagen esté ya de suyo estetizada, pues la estetización es un proceso de índole social que afecta solo a algunas imágenes y ello solo en determinadas circunstancias" (Vilar, 2012: 7). En nuestro caso, lo que se quiere señalar con esta expresión es cómo, mediante un proceso inevitable en el recorrido vital de estas obras, ha sido el carácter estético el que ha adquirido prioridad frente a su dimensión como artefactos de resistencia y de lucha. Es decir, "llamamos estetización al proceso por el que la dimensión estética de algo, especialmente de las imágenes, adquiere un sobrepeso o prioridad frente a sus otras dimensiones (normativa, cognitiva, etc.)" (Vilar 2012: 9). Con ello no se pretende en absoluto depreciar el valor crítico de las estampas, sino reflexionar acerca de las modalidades y los procesos culturales en los que las imágenes son difundidas, interpretadas y transformadas. 
Becker, Carol: "Private Fantasies Shape Public Events: And Public Events Invade and Shape Our Dreams". En http:// www.thefileroom.org/publication/becker.html [14-VIII-2015].

Bozal, Valeriano (1966): El realismo, entre el desarrollo y el subdesarrollo, Madrid: Ciencia Nueva.

Dapena, María Francisca (1978): ¿Sr. Juez! (soy presa de Franco...), San Sebastián: L. Haranburu.

De Haro, Noemi (2010): Grabadores contra el franquismo, Madrid: CSIC.

De Nicolás, Vidal/Giménez Pericás, Antonio (1962): Estampa Popular de Vizcaya, San Sebastián: [s.e.].

Gandía Casimiro, José (1996): Estampa Popular, Valencia: IVAM.

García-Landarte Puertas, Valeria (2004): "Estampa Popular de Vizcaya. El realismo social de los años sesenta en el País Vasco", trabajo de investigación inédito realizado con beca de la Fundación BBK.

García-Landarte, Valeria (2006): "Estampa Popular de Vizcaya. El realismo social de los años 60 en el País Vasco". En: Ondare. Cuadernos de Artes Plásticas y Monumentales: revisión del Arte Vasco entre 1939-1975, n. ${ }^{\circ} 25$, pp. 393 401.

Giménez Pericás, Antonio (1961): “Despersonalización de arte y sociedad”. En Acento Cultural, Madrid, n. ${ }^{\circ} 11$, pp. $37-$ 44.

Guasch, Ana María (1985): Arte e ideología en el País Vasco, 1940-1980, Madrid: Akal.

Llorens, Tomás (1963): "Realismo y arte comprometido". En: Suma y Sigue del Arte Contemporáneo, Valencia, n. ${ }^{4} 4$, pp. 12-16.

Macazaga, Leire (2013): “Grabadores vascos de las décadas de los 60 y 70”, Tesis Doctoral, Universidad del País Vasco $\mathrm{UPV} / \mathrm{EHU}$

Macazaga, Leire (2014): "La obra gráfica de María Francisca Dapena durante el tardo franquismo y la transición. La única artista integrante de Estampa Popular de Vizcaya". En: Artigrama, n. ${ }^{\circ} 29$, pp. 433-450.

Marrodán, Mario Ángel (1988): Panorama de la Acuarela Vasca, Bilbao: Banco Bilbao Vizcaya.

Moreno Galván, José María (1963): "El realismo social que pasa por Madrid”. En: Suma y sigue del arte contemporáneo, n. ${ }^{\circ}$ 3, Valencia, pp. 33-40.

Puig, Arnau (2005): Cap una altra realitat. El context d'Estampa Popular, Girona: Museu d'Art de Girona.

Retana, José María (1980): Pintores y escultores vascos de ayer, hoy y mañana I (4), Bilbao: La Gran Enciclopedia Vasca.

Vega, Jesusa (2008): "La técnica artística como método de conocimiento, a propósito de El Coloso de Goya". En: Goya, n. ${ }^{\circ} 324$, pp. 229-244.

Vilar, Gerard (2012): "La estetización de la imagen violenta en el arte contemporáneo". En: García Ana (ed.): Filosofia e(n) imágenes, Zaragoza: Institución "Fernando el Católico" Organismo autónomo de la Excma. Diputación de Zaragoza, pp. 7-22.

VV.AA. (1962): Arte Norte y Sur, Córdoba: [s.e.].

VV.AA. (2000): Ezkerraldea Plastika. Artistas Plásticos de la Margen Izquierda y Zona Minera (vol. X), Bilbao: Diputación Foral de Bizkaia.

VV.AA. (2007): El movimiento Estampa Popular en la Colección UC de Arte Gráfico, Santander: Universidad de Cantabria.

Fecha de recepción: $30-\mathrm{XI}-2015$

Fecha de aceptación: 24-II-2016 